\title{
GROWTH ACCOUNTING IN TIMES OF TURBULENCE AND \\ DEATH: EFFICIENCY, TECHNOLOGY, CAPITAL \\ ACCUMULATION AND HUMAN CAPITAL 1929-1950
}

\author{
Kerstin Enflo* and Joerg Baten** \\ * Lund Univ. and Univ. Pompeu Fabra, email: kerstin.enflo@ekh.lu.se \\ ** Univ. of Tuebingen, Univ. Pompeu Fabra, and CESifo
}

\begin{abstract}
:
We employ a non-parametrical approach to growth accounting (Data Envelopment Analysis, DEA) to disentangle the proximate sources of labour productivity growth in 41 nations between 1929 and 1950 by decomposing productivity growth into four components: technological change; efficiency catch-up (movements towards the production frontier), capital accumulation and human capital accumulation. We show that efficiency catch-up generally explains productivity growth, whereas technological change and factor accumulation were limited and distorted by the effects of war. War clearly hampered efficiency. Moreover, an unbalanced ratio of human capital to physical capital (a gap to the technological leader) was crucial for efficiency catching-up.
\end{abstract}

JEL codes: N10, N40, O47

Keywords: DEA, growth accounting, productivity, interwar period

We thank seminar participants at Univ. Pompeu Fabra, Univ. Carlos III. de Madrid, Univ. Tuebingen, especially Luis, Bértola, Albert Carreras, Dorothee Crayen, Astrid Kander, Kirsten Labuske, Leandros Prados, Joan Roses, Mar Rubio, Lennart Schoen, and Jeffrey Williamson for important suggestions. The Marie Curie RTN program provided financial support. 
GROWTH ACCOUNTING IN TIMES OF TURBULENCE AND

DEATH: EFFICIENCY, TECHNOLOGY, CAPITAL

ACCUMULATION AND HUMAN CAPITAL 1929-1950 


\section{GROWTH ACCOUNTING IN TIMES OF TURBULENCE AND} DEATH: EFFICIENCY, TECHNOLOGY, CAPITAL ACCUMULATION AND HUMAN CAPITAL 1929-1950

\section{Introduction}

Growth accounting has long been an important tool to disentangle the proximate sources of economic growth (Solow: 1957, Griliches and Jorgenson: 1967). However, the method requires several assumptions about perfect competition in markets, the functional form of the production technology in use, Hicks-neutral technological change and constant factor shares in income. The majority of growth accounting studies has assumed that output is produced according to a two-input Cobb-Douglas aggregate production function. This reliance was questioned by Duffy and Papageorgiou (2000), who found that they could reject the CobbDouglas specification using a panel of 82 countries over a 28 year period. Furthermore, crosscountry evidence suggests large variances in labour shares of countries at various stages of development (Gollin: 2000). In addition, growth accounting results tend to be biased in the presence of inefficiency in the production process (Grosskopf: 1993).

Given some of the above-mentioned draw-backs, Kumar and Russell (2002) argue in favor of using a non-parametrical approach to growth accounting that neither requires assumptions about absence of market imperfection nor about the specific form of the production technology. In this study, we follow their reasoning and argue in addition that the notion of relative efficiency, or inefficiency, should be taken into account when performing historical growth accounting exercises, in particular during times of disintegration and war. In such turbulent situations institutional frameworks, access to world markets, war participation and the general economic environment are more likely to influence how efficient a country can transform the use of inputs into outputs. 
The interwar and immediate post-war periods are interesting to study from this perspective since this period saw limited technological diffusion as countries became increasingly closed from world markets. In addition, the period was one of very modest capital growth in a majority of countries. In technological leading nations as USA and UK capital per worker hardly accumulated at all. In general, the period 1929-1950 saw the least capital growth per worker since 1890 (see Maddison: 1995). Nevertheless, there were increases in labour productivity during this period. Countries like Sweden, South Africa and Portugal nearly doubled in labour productivity between 1929 and 1950 whereas increases in Canada, Finland, Norway, Brazil, USA and New Zealand were substantial as well (around 50 percent). Foreman-Peck (1995, pp. 182-83) notes the paradox in that declining international trade, unemployment and general instability was accompanied by considerable real income increases in many countries. Foreman-Peck argues that prosperity of the time period was based upon the adoption of the revolutionary technologies from the late $19^{\text {th }}$ century, especially the applications of electricity, the internal combustion engine and the factory mode of production that offered scopes for catching-up.

However, the scope for catching-up could be dependent on the general "social capability" of a nation, as argued by Abramowitz (1986). The general social capability of a nation can be seen as a component of human capital which can abridge the process of technology adoption for late-comers. At the start of the $20^{\text {th }}$ century the rich nations had converged in terms of elementary-school enrolments and many of the poorer countries had started to expand mass primary schooling (Goldin: 2001, p.265). These educated cohorts started to enter into the workforce during the 1920's and 1930's and could have affected the general propensity for catching-up in certain nations, despite the world disintegration.

In this article we aim at clarifying the inter-war growth puzzle, especially focusing on the sources of catching-up and on the growth effects from human capital. There is a strong 
case for measuring inter-war growth from 1929 to 1950 by means of non-parametrical growth accounting that do not require perfect market assumptions but take factor accumulation and efficiency changes into account. Moreover, we argue that the process of catching-up can be measured as increases in efficiency relative to the best practise nations in the sample. We also investigate the exogenous determinants of such catching-up effects, hypothesising that institutional frameworks and war participation mattered, but also that countries with high human capital components were better equipped to increase productive efficiency and catchup.

\section{Method}

\subsection{Data Envelopment Analysis (DEA)}

The study utilizes Data Envelopment Analysis (DEA) which is a data-driven non-parametric linear programming method that neither requires any a priori specifications of the functional form of the technology nor any assumption about market structure and absence of market imperfections. It does however require an assumption of the returns to scale of the technology.

This non-parametrical approach to growth accounting was pioneered by Färe et al. (1994) who decomposed the labor productivity increases in 17 OECD countries 1977-1988 into technical change and efficiency change. The decomposition has recently extended to incorporate capital accumulation (Kumar and Russell: 2002, Los and Timmer: 2005) and human capital accumulation (Henderson and Russell: 2005) as sources of labor productivity growth in a sample of countries post 1965.

More formally, assume that the production set is spanned by a set of input and output vectors. More formally, let $\Psi=\left\{(X, Y) \in \mathrm{R}^{\mathrm{N}+\mathrm{M}}\right\}$. That is, the set of $N$ inputs, measured by the vector $X$, can produce $M$ outputs, measured by vector $Y$. All efficient production plans lie on 
the boundary (frontier) of the production set $\Psi$ (Debreu: 1959). The relative efficiency scores, $\lambda$ are calculated from a set of observations $\left\{\left(x_{i}, y_{i}\right) ; i=1, \ldots, n\right\}$ by solving a linear programming problem, where $x$ and $y$ denotes the sample input and output vectors, respectively, and $n$ denotes the number of observations in the sample (Färe et al.: 1994b). More precisely, the estimated DEA scores $\left\{\hat{\lambda}_{i}=\hat{\theta}_{i}^{-1} ; i=1, \ldots, n\right\}$ of the attainable set $\Psi$ are defined as:

$$
\hat{\theta}_{i}\left(x_{i,} y_{i}\right)=\sup \left[\theta \mid\left(x_{i} \theta y_{i}\right) \in \hat{\psi}\right] ; i=1, i \ldots, n
$$

where the subset $\hat{\psi}$ is spanned by the sample input and output vectors $\left\{\hat{\psi}=\left(x_{i}, y_{i}\right) \in \mathfrak{R}^{N+M} ; i=1, \ldots, n\right\}$. The index is the inverse of the maximal proportional amount that output $y_{i}$ can be expanded given the input quantities $x_{i}$ and the existing technology.

\subsection{Decomposition Analysis}

In order to disentangle the proximate forces of labour productivity growth, we follow the methodological approach of Henderson and Russell (2005, pp.1178-1180). Exploiting the constant returns to scale assumption, we use the obtained productivity frontiers and relative efficiency scores to decompose productivity growth into four components: technological change (shifts of the production frontier); technological catch-up (movements towards or away from the production frontier), capital accumulation and human capital accumulation (movements along the production frontier) between our benchmark years. Disentangling the contributions from technological change, capital and human capital accumulation are standard to growth accounting analyses, although we measure them without any assumptions about the functional form of the production technology. More importantly however, the addition of 
relative efficiency enables us to analyse the catching-up and decline of nations compared to the technological frontier as well.

Following Henderson and Russell (2005, pp. 1178-1180) let $\hat{y}_{b}\left(\hat{k}_{b}\right)$ and $\hat{y}_{c}\left(\hat{k}_{c}\right)$ denote output per efficiency unit of worker and $e_{b}$ and $e_{c}$ the estimated efficiency indices in the current, $c$, and base period, $b$, respectively. By definition, the potential output per efficiency unit of worker in the two periods are $\bar{y}_{b}\left(\hat{k}_{b}\right)=\hat{y}_{b}\left(\hat{k}_{b}\right) / e_{b}$ and $\bar{y}_{c}\left(\hat{k}_{c}\right)=\hat{y}_{c}\left(\hat{k}_{c}\right) / e_{c}$. We can therefore write the ratio of labor productivity in the current to the base period as the product of the estimated efficiency indices and the potential output in each period

$$
\frac{\hat{y}_{c}}{\hat{y}_{b}}=\frac{e_{c} \times \bar{y}_{c}\left(\hat{k}_{c}\right)}{e_{b} \times \bar{y}_{b}\left(\hat{k}_{b}\right)} .
$$

Now, define the potential output per efficiency unit of worker at the current period capital per worker ratios, given the technology that was in existence at the base period, as $\bar{y}_{b}\left(\hat{k}_{c}\right)$. Similarly define $\tilde{k}_{c}=K_{c} /\left(L_{c} H_{b}\right)$, thus the capital per worker ratio in the current period under the counterfactual assumption that the human capital augmentation did not change since the base period. Multiplying the top and bottom of (2) with $\bar{y}_{b}\left(\hat{k}_{c}\right) \times \bar{y}_{b}\left(\tilde{k}_{c}\right)$ results in the following decomposition of labor productivity growth per efficiency unit of worker

$$
\frac{\hat{y}_{c}}{\hat{y}_{b}}=\frac{e_{c} \times \bar{y}_{c}\left(\hat{k}_{c}\right) \times \bar{y}_{b}\left(\tilde{k}_{c}\right) \times \bar{y}_{b}\left(\hat{k}_{c}\right)}{e_{b} \times \bar{y}_{b}\left(\hat{k}_{c}\right) \times \bar{y}_{b}\left(\hat{k}_{b}\right) \times \bar{y}_{b}\left(\tilde{k}_{c}\right)} .
$$


Growth in labour productivity $y_{t}=Y_{t} / L_{t}$ can in turn be decomposed into the growth of efficiency output per worker and the growth of the human capital augmentation factors.

$$
\frac{y_{c}}{y_{b}}=\frac{\hat{y}_{c}}{\hat{y}_{b}} \times \frac{H_{c}}{H_{b}}
$$

Combining equation 3 and 4 yields the following decomposition of labour productivity growth into four factors:

$$
\frac{y_{c}}{y_{b}}=\frac{e_{c}}{e_{b}} \times \frac{\bar{y}_{c}\left(\hat{k}_{c}\right)}{\bar{y}_{b}\left(\hat{k}_{c}\right)} \times \frac{\bar{y}_{b}\left(\tilde{k}_{c}\right)}{\bar{y}_{b}\left(\hat{k}_{b}\right)} \times \frac{\bar{y}_{b}\left(\hat{k}_{c}\right) \times H_{c}}{\bar{y}_{b}\left(\tilde{k}_{c}\right) \times H_{b}}
$$

$$
=E F F \times T E C H \times K A C C \times H A C C
$$

corresponding to movements towards or away from the productivity frontier (the efficiency change, $E F F$ ); the shift of the productivity frontier at the current periods capital per efficiency unit of worker levels (technical change, TECH); the capital accumulation along the base periods productivity frontier $(K A C C)$; and the effects of human capital accumulation $(H A C C)$.

This decomposition measures technological change at current period's capital per efficiency unit of worker levels and capital accumulation along the base period's productivity frontier. However, the composition can also be made the other way around (thus technical change at the base periods capital levels and capital accumulation along the current frontier). The two decompositions will not yield the same result unless technology is Hicks neutral, i.e. augmenting capital and labour by the same proportion at different capital per worker ratios. ${ }^{1}$ It shall however be emphasized that this problem is endemic to the task of growth accounting and is usually resolved by simply assuming Hicks neutrality of technical change.

\footnotetext{
${ }^{1}$ See Henderson and Russell (2005, p. 1179) for a more detailed description of the path-dependency of the two decompositions.
} 
Following Kumar and Russell (2002) and Henderson and Russell (2005) we resolve the ambiguity of choosing between the two decompositions by taking the Fisher average of the decomposed factors in the following way:

$$
\frac{y_{c}}{y_{b}}=E F F \times\left(T E C H^{b} \cdot T E C H^{c}\right)^{1 / 2} \times\left(K A C C^{b} \cdot K A C C^{c}\right)^{1 / 2} \times\left(H A C C^{b} \cdot H A C C^{c}\right)^{1 / 2}
$$

\section{Data}

For this study we have put together a unique data set of GDP, labour, capital and human capital for 41 countries around the world for the benchmark years 1929, 1938 and 1950. We have collected GDP and labour figures from a number of sources, however relying foremost on the Maddison: 1995 dataset.

Since internationally comparable data on physical capital stocks is unavailable for a large number of countries before 1965 we estimate the amount of physical capital on basis of energy consumption data taken from Darmstadter (1971). This strategy has originally been developed for estimating socialist and communist countries' physical capital (Gregory: 1975) but we show that it can also be applied to early $20^{\text {th }}$ century "white spots". The advantage of measuring capital stocks from energy consumption data is first of all that data is internationally comparable, thus avoiding the issues of differing average service lives and depreciation speeds in capital stocks (O’Mahoney: 1996) and problems of sectorial deflation. Secondly, energy consumption provides a direct estimate of the share of the capital stock that enters into useful production, which makes our estimate lie closer to the notion of capital services than capital stock. We believe that this measure is even more accurate in growth accounting studies. See appendix A1 for a detailed description of the capital stocks. 
For human capital stock estimates we follow the approach of obtaining human capital augmentation factors by Hall and Jones (1999). The approach builds on the Psacharopoulos (1994) world wide survey of the returns to education and Lindert's (2006) data on schooling enrolment (and the suggestions for interpolation by Labuske and Baten 2006), from which we estimated average years of schooling in each population for our benchmark years. In appendix A2, the estimation of human capital augmentation factors is described.

The average increase in the augmentation factors in our sample was 6 percent between 1924 and 1945 and there was a weak convergence in human capital accumulation, with France and Sweden showing very modest increases and the largest increases in Japan, Chile and Finland (16 percent). Figure 5 displays the calculated human augmentation factors for all 41 countries in 1925 and 1945. Human capital increases were also large in countries like South Africa, Turkey and Sri Lanka. The French human capital evolution stands out in this figure, mainly because of its special demographic development. Lindert (2004a) found that the French schooling rate before WWI was often underestimated, because earlier studies did not take the rapid decline of the number of children in the school age over the $19^{\text {th }}$ century (age 5-14) into account. Lindert corrected those figures, and estimated a higher value. Those pre-war schooling investments led to a elevated number of school-year of the labour force (age 25+) in the 1920s. In contrast, the post-WWI government in France had substantial economic problems, which - among other factors - led to more average schooling investments in the early 1920s, which filtered into a lower stock of school years available in the adult labour force of the 1940s.

\section{Results}

\subsection{Technical frontiers}


Figure 1 and 2 shows the estimated production frontiers in 1929 and 1950 respectively. Figure 1 displays the frontier estimated using only capital and labour as inputs whereas figure 2 shows the frontier after we have included the human capital augmentation factors. Note that the scale of the production frontier changes after we measure capital and output per efficiency unit of labour. The assumption of constant returns to scale and labour augmentation of the labour force allow us to display the constructed frontiers in two-dimensional space. Several features stand out from the figures. First of all, we can identify the technological leading nations as the countries that determine the frontier in every benchmark year. We find that United States lies on the technological frontier at different capital levels for all benchmark years. This remains true both if we include human capital and if we do not. It appears that our identification of the frontier countries (the technological leaders) remains relatively robust to the human capital inclusion. In 1929 Argentina, Netherlands, and United States determined the production frontier at relatively high capital per worker levels, both with and without the inclusion of human capital. Switzerland was however excluded from the production frontier in 1929 after we included human capital in the production process. In 1950 the same countries determined the frontier using both specifications. Apart from the case of Switzerland in 1929, this indicates that the frontier countries were fully exploiting the returns to human capital and that their technology remained "best practise" even after controlling for the higher value of their workforce due to education.

At low capital per worker levels the frontier is determined by Thailand and Sri Lanka in 1929 both with and without human capital inclusion. At these low capital per worker levels the frontier does not shift at all during the investigated time period, showing that technology was non-neutral and that there were limited scopes for technological change for the least productive nations in the time period. 
When investigating how the frontier shifted over time, we find that including human capital into the productivity analysis severely modifies the shifts of the production frontier (the expansion of potential output, which can be interpreted as technical change). Between 1929 and 1950 the frontier shifted by a third at medium capital per worker levels when we do not control for human capital, but only by a fifth at medium levels after the human capital inclusion. Thus, slightly less than half of the effects of technological change could be attributed to human capital increases at medium capital per worker levels between 1929 and 1950.

We have also calculated the production function for the benchmark year 1938, but we find that the frontier does not shift at all between 1929 and 1938 after we include human capital, showing the negative effects that the Depression had on potential output (after controlling for human capital accumulation).

\section{2 Technical Frontiers and Relative Efficiency, with and without human capital}

Table 1 lists the efficiency indices for our 41 countries in 1929 and 1950 calculated under the assumption of constant returns to scale. For comparison purposes we present the relative inefficiency of countries both with and without the inclusion of human capital in the production function. Countries with efficiency indices of 1 it are fully efficient given their relative inputs and thus determining the technological frontier at the given time period. As seen from the table, the inclusion of human capital improves the efficiency of the majority of countries (those in bold text), especially in 1950. This finding points to the fact that low levels of human capital relative to the frontier countries can explain a substantial amount of the estimated country-level inefficiency and that the importance of this gap was growing with time. 
Some countries look better in terms of efficiency after we took their low human capital into account: The largest difference after accounting for human capital in 1950 were found in South Africa, Mexico, Nicaragua and Chile. In contrast, the efficiency of Japan and Hungary declines after we include human capital in 1950, meaning that these two countries did not fully utilize their stocks of human capital efficiently in relation to similar countries. This might have been a result of the war events taking place directly before 1950 .

The finding that the efficiency in most countries improves after we include human capital indicates that low levels of human capital could explain parts of the estimated inefficiency levels. Thus, there is a level effect from human capital to the level of relative inefficiency. However, in order to assess the growth contributions from changes in capital, capital, efficiency and technical shifts, we continue with the decomposition analysis outlined in section 2.2.

\section{3 Decomposition Analysis}

In table 2 the results from the decomposition analysis outlined in section 2.2 are given. We have carried out the decomposition between 1929 and 1950 for all of our 41 sample countries and for comparison purposes we present the result both with and without human capital. As seen from the averages of the relative contributions to labour productivity growth at the bottom row of the table, the 41 countries increased labour productivity by 24 percent on average, but were relatively falling behind the productivity frontier as the relative efficiency contribution was - $19 \%$ on average when we do not include human capital in the decomposition. The moderate contribution of technical change comes from the fact that the frontier shifted relatively little during our time period. In addition, controlling for human capital cuts the contribution of technical change by a third. This shows that some of the modest shifts of the frontier could be accommodated for by quality improvements of the 
workforce. Adding human capital to the production specification severely modifies the growth contribution of capital accumulation, probably because capital per efficiency unit of labour decreased in many countries between 1929 and 1950.

Thus, between 1929 and 1950 the relative growth contributions of capital accumulation and technical change appear to have been modest. This fits well with the fact that the world was disintegrated and turbulent. In addition many countries were falling behind the productivity frontier, showing how world disintegration and wars contributed to efficiency collapses in many countries. The strongest positive effect comes from the fact that human capital continued to increase as the educated cohorts of the 1910's and 1920's entered into the workforce. The effects of human capital accumulation were however counteracted by slow capital accumulation and efficiency collapses, for example in Poland, Japan, and China. It seems that although human capital had strong relative growth effects during this time period, the effects were counterbalanced by slow capital accumulation and efficiency collapses, features that can mainly be attributed to the specific conditions of our investigated time period.

Table 3 summarizes the correlations between the four decomposed sources with labour productivity growth between 1929 and 1950.

Table 3. Correlations between labour productivity growth and the decomposed sources 1929-50

\begin{tabular}{cccc}
\hline \hline EFF & TECH & KACC & HACC \\
\hline 0.68 & 0.14 & 0.57 & -0.42 \\
\hline
\end{tabular}

The first element in the table displays that efficiency changes correlate very well with productivity increases. Thus, although the majority of countries were falling behind the production frontier, there were a few growth miracles that caught-up with the technological 
leaders and increased output. Sweden and South Africa show strong efficiency and productivity increases, but we find similar patterns in New Zealand, Norway, Canada, Mexico and Switzerland.

The next element indicates that the relative contributions of frontier shifts are ambiguous. As mentioned earlier, the frontier did not shift at all between 1929 and 1938 and the shift was modest for the full period, especially at low capital per efficiency unit of worker levels. Thus, we find low contribution from technology in Thailand and Sri Lanka, since the technological frontier hardly shifted at their capital per efficiency unit of worker levels. In the rest of the sample, the shift of the frontier at various capital per worker levels does not show any systematic correlation to productivity increases. Rather, it seems that the movements towards or away from the frontier, the "catching-up forces", were more important in explaining productivity increases.

In the two last columns in table 3 we correlate capital and human capital accumulation against labour productivity growth. The rather strong correlation between capital accumulation and productivity growth designates that although the size of the relative effects of capital accumulation was relatively small and sometimes even negative, countries with positive gains from capital also experienced productivity growth. On the other hand, the growth effects from human capital increases were great in magnitude, but the most prevalent effects were found in countries with collapsing productivity and efficiency levels. The story is consistent with the evidence from Poland, Japan and China. Human capital accumulation was the only productive accumulation force that was relatively undistorted in countries were capital was destroyed and efficiency collapsed. However, increases in human capital alone could not drive productivity increases.

This section concludes that although the contributions from factor accumulation played a role, the accumulation of capital was slow. In many cases capital per efficiency unit 
of worker actually decreased. Moreover, technological change took place at a slow rate and shifts in the production frontier do not appear to explain why some countries were still able to achieve labour productivity growth. Rather, we find that this period was one in which inefficiency was a substantial element in the production process and that many countries were falling behind the production frontier. In addition, efficiency increases correlate well with labour productivity growth, indicating that we need to understand the determinants of efficiency change, especially in a time period of slow factor accumulation and limited technological change.

\subsection{What determines efficiency in the de-globalisation and war period?}

In this section we explore potential determinants of efficiency growth or decline between 1929 and 1950. We will use regression analysis in order to find the determinants of efficiency change. This approach, where efficiency is estimated in the first stage and thereafter regressed upon various exogenous covariates is generally known as the two-stage approach (see for example Ray 2004). We are particularly interested in phenomena which might have kept markets from working, hence retarding the adoption of new technologies.

We imagine that a protectionist policy might be such a force in the interwar period: if a country lifts its tariff barriers to abnormally high levels, it might not only benefit from "beggar your neighbour" effects, but it might also deter the imports of capital good and new technologies. For example, the extreme cases of high tariffs were the countries Colombia, Portugal and Brazil. Argentina's import-substitution policy in the 1940s and 1950s is another example of tariffs driving up equipment prices and depriving the industry of technology import (Taylor: 1992).

However, as argued by Collins and Williamson (2001, pp. 77), tariffs can have different effects on the relative price of capital goods depending on the time and the place. 
Collins and Williamson investigate the connection between tariffs and the relative price of capital in 11 OECD countries $1870-1950$ and find that tariffs generally favoured capital goods relative to consumer goods to the extend that they distorted relative prices prior to 1950 . Thus, the effects on tariffs on efficiency and technology adoption is ambiguous for the period prior to 1950 . In order to test how tariffs affected efficiency growth for our larger dataset (that has the advantage of including a number of Latin American countries) we use average tariff rates from the Clemens and Williamson (2004) dataset. The tariffs are measured as the share of customs revenues (import duties only) in total import values. Figure 5 shows the average tariff rates in 1929 and 1938 for a majority of the countries in our dataset.

Another big source of market distortions was the Second World War. What happened to those countries that had particularly high blood loss? Or that participated longest in the Second World War and other major conflicts between 1929 and 1949? Was there a special efficiency loss among the losers of wars? Did geographic location and being outside Europe, where a large share of the war activity took place, matter for efficiency growth?

We model those questions by considering the log number of battle deaths per pre-war population, the log number of war days per country in this period, a dummy variable indicating whether a country lost any war during this period, and a dummy variable if the country was situated outside of Europe. The data concerning the war variables were taken from the Correlates of War Dataset (www.correlatesofwar.org). We assume that all those factors were detrimental for economic efficiency, and we argue that if a country lost a war, but won others, the losing effect was stronger. Japan would be an example here.

Apart from the variables that measure impediments to the function of international markets, there are a number of internal factors that may hamper efficiency growth, for example civil wars. We added a dummy variable for civil war conflicts during this period (such as the Spanish civil war). 
We also imagine that domestic price volatility would have strong effects on uncertainty, making an efficient choice of the most appropriate production plan more difficult. Hence, we analyze the effect of internal economic turbulence by adding a pricevolatility variable that captures the ration between the highest and lowest recorded price during the investigated time period. Price data are taken from Mitchell.

A large recent literature has also focused on the contributions of a stable and competent state as a contributing factor to economic growth. Bockstette et al. (2002) have compiled a comprehensive data set of state institutions. They were particularly interested in the antiquity of states, interpreting the efficiency of governance institutions as function of the experience a certain country had with governments in history. For example, China and Italy had long run experiences with state organization, whereas Zambia had only recently developed government institutions which covered a large share of its territory. The authors find that the antiquity of states has a strong positive impact on the 1960-90 growth rates, ceteris paribus. While we imagine that state antiquity could have had a positive impact on efficiency growth in the interwar and war period, we would also formulate the counterhypothesis: Countries with a historically strong national government might be more involved in the war conflicts of the Second World War, mobilizing more resources for warfare. More decentralized and newly settled countries might on the other hand be less involved, and a smaller share of their resources can be mobilized for warfare.

Finally, inspired by the concept of social capability as a source of catch-up and, we are interested in the social and institutional factors that may facilitate the diffusion and adoption of technologies. For the post-war period Toniolo (1998) has convincingly argued that a favourable ratio of human capital to physical capital was conducive for European catch-up with the USA during the Golden Age. Toniolo argues that USA as a technological leader was long characterized by a much higher capital to labour ratio than the rest of the world. The 
difference increased due to the Second World War, since countries on the Continent suffered considerable losses in industrial plants and public capital. However, since schools and universities continued to function rather well the difference in human capital levels was not as large as it was in physical capital between USA and the rest of the world. This gap between potential output and actual output per worker, measured as the relative ratio of human capital to physical capital is a typical condition favourable for catch-up growth and efficiency increases. We are interested in examining whether this hypothesis can also be verified as a source of catching up in the inter-war period. As the First World War resulted in losses in physical capital simultaneously with the educated cohorts born in the early $20^{\text {th }}$ century entering into the labour force, we hypothesise that countries with relatively high human capital to physical capital in 1925 were generally more likely to experience the "brain to capital gap" and efficiency catch-up with USA as the technological leader. We measure the propensity for "brain to capital gap" as the ratio between the number of school years in 1925 and the capital stock in 1929. A frequent problem wth ratios is that one variable has a much larger variance, hence the overall variance is determined by this variable. For example, if you calculate the ratio of literacy and GDP, and literacy would always be $100 \%$, then all the variation in the ratio variable would come from GDP. In order to avoid this problem, we used the $\log$ of capital stock, and standardized both variables to an index between 0 (=minimum value) and 100 (maximum), before calculating the ratio.

Many of the above-mentioned variables are only available for a subset of countries between 1929 and 1950. Hence we can only perform exploratory regressions that cannot take all possible determinants into account. In the following, we will focus on cross-sectional regressions. We considered whether to transform our data set into a panel format, and estimate fixed effects, in order to avoid the usual problems of unobserved heterogeneity. However, at least two counter-arguments prevent us from chosing a FE specification: first of 
all, most of our explanatory variables are time-invariant, hence they would drop out of a simple FE approach. Secondly and more important, growth panel analyses with FE approaches have been criticised, as they put so much more emphasis on the variation over time, and ignore mostly the variation between countries (Durlauf 2005). The variation over time though, it has been argued, is more likely to be distorted by measurement error, compared to the variation between countries. This is especially true when it comes to factors as hard to measure as human capital, and institutions.

The regression results are found in Table 3. Model I to III refer to the whole time period, whereas models IV to VI focus specifically on the most turbulent war years 19391950. First of all, it is evident from the table that the brain to capital gap variable is significantly and positively related to efficiency growth in all six regressions. Thus, countries that had a relatively high human capital to capital ratio in 1925 ("brain to capital gap") achieved higher efficiency growth in subsequent periods, no matter whether we focus on the war years or on the full sample period. This variable is not only statistically, but also economically significant: a standard deviation change in the brain to capital gap is 0.35 (Table 4). Such a change would imply an efficiency change of 0.12 (using the coefficient of Model I). This is a substantial proportion of the overall standard deviation of the efficiency change between 1929 and 1950, which is 0.27 .

In contrast, protectionism measured as average tariff rates apparently did not play a strong role for efficiency growth, as the coefficient of variable is insignificant in the first model. This result is in line with the Collins and Williamson (2001)-argument about ambiguous tariff effects prior to 1950. In model II we include the state antiquity variable but find that this variable cannot explain efficiency growth in our time period.

However, the other market distortion and turbulence variables receive stronger support. Market distortions measured as the effects of war is significant with the expected 
sign in different combinations in most models. Losing one war has a negative effect for the full period in model III when we do not control for tariffs and the war durations is negatively related to efficiency growth for the war years 1938-50. However, the blood toll was not a significant contribution to efficiency decrease (Model VI).

From all six model specifications we find that starting a civil war appears to have been a very consistent and significant method of ruining a country's efficiency. Again, not only statistical, but also economic significance is clearly given. Being outside of Europe where most of the battles took place also appears to have had a positive impact on efficiency in most models.

Finally, price volatility in 1929-38 had the expected negative impact on efficiency growth in all specifications, apart from the first model in which we control for tariffs but are restricted to 27 observations. Statistical significance is given for the 1938-50 efficiency change.

\section{Summary and Conclusions}

We have employed a non-parametrical approach to growth accounting for 41 countries during the inter-war and war years 1929 to 1950 . We have shown that inclusion of human capital to the production function modifies growth accounting results (a level effect of human capital). The majority of the sample countries improve in efficiency after human capital was included especially for later period. This is a sign that low levels of human capital partly explain the estimated inefficiency and that the effect was growing with time. Adding human capital also cut the relative contribution of technological change (shifts in the production frontier) by a third on average in the sample. 
However, the countries that were determining the technological frontier were not affected by controlling for human capital, indicating that the leading countries were fully able to utilize their human capital levels in the production process.

Looking at the relative contributions of changes in efficiency, technology and human capital accumulation using the decomposition method shows a slightly different picture. Although the growth effects from human capital increases were large in magnitude, the countries that showed the largest contributions from human capital increases were not the same as the countries that had the strongest labour productivity growth during the time period. Instead, it appears that the possibility to move towards the production frontier and increase efficiency was more important in explaining productivity growth during the interwar and war years. This finding shows that much of the productivity increases in the inter-war period stemmed from the forces of catching-up, perhaps due to the successful adoption of the technologies from the late $19^{\text {th }}$ century (electricity, combustion engine, factory mode of production) and the possible effects of brain to capital gap due to capital destruction in the First World War and human capital investments at the turn of the century. The growth contributions from countries catching-up with the technological frontier also underlines the importance of adding the notion of inefficiency into the growth accounting framework, especially when technological change and factor accumulation is limited and distorted by the effects of war.

Explaining the efficiency changes with the use of regression analysis confirms this view. Countries with long war duration, civil wars and countries that lost wars exhibit lower efficiency improvements, or even declining efficiency. On the contrary, having a high initial level of human capital before the war relatively to the capital stock appears to have created a gap between actual and potential output that was had similar favourable effects for catchingup in terms of efficiency increases as we have seen for the post World War 2 period. 
Thus, exogenous global phenomena as wars certainly matter for productive efficiency, but we find strong level effect from human capital on both productivity growth and efficiency growth as well. Hence, we need to distinguish between growth effects and level effects of human capital. Growth effects influenced labour productivity directly, but only modestly during this period, whereas the level effects impacted of countries ability to catch-up with the technological leaders and thus indirectly on labour productivity. This result is robust even in times of turbulence and death. 


\section{References:}

Abramowitz, Moses (1986), “Thinking About Growth: Catching Up, Forging Ahead, and Falling Behind", Journal of Economic History 46, 385-406

Bockstette, Valerie, Chanda Areendam and Louis Putterman (2002) "State and Markets: The Advantage of an Early Start", Journal of Economic Growth, vol. 7 pp. 347-369.

Clemens, Michael and Jeffrey Williamson (2004): "Why did the Tariff-Growth Correlation Change after 1950?”, Journal of Economic Growth, 9, pp. 5-46

Collins, William and Jeffrey Williamson (2001) "Capital -Goods Prices and Investment 1870-1950”, Journal of Economic History, vol. 61, No,1

Darmstadter, Joel, Teitelbaum, P.D and Polach, J.G. (1971): Energy in the World Economy A Statistical Review of Trends in Output, Trade, and Consumption since 1925

Debreu, G. (1959) Theory of Value, Yale University Press.

Duffy, J., Papageorgiou, C., (2000). "A cross-Country Empirical Investigation of the Aggregate Production Function Specification”. Journal of Economic Growth 5, 87-120.

Durlauf, Steven N. et al. (2005) "Growth Econometrics”, Handbook of Economic Growth, Vol. 1A, North-Holland., pp. 555-677. 
Foreman-Peck, James (1995) A History of the World Economy - International Economic Relations since 1850, Harvester Wheatsheaf, second edition

Färe, R., Grosskopf, S., Morris M. and Zhang Z. (1994) "Productivity growth, technical progress and efficiency in industrialized countries", American Economic Review, 84(1), pp. 66-84.

Gregory, Paul (1975) "Some Indirect Estimates of Eastern European Capital Stocks and Factor Productivity", Soviet Studies, 27, 71-85

Griliches Z. and D.W. Jorgenson (1967) "The explanation of productivity change" Review of Ecomics and Statistics, vol. 34 no. 3, pp. 249-283

Gollin, Douglas (2002) “Getting Income Shares Right”, Journal of Political Economy, vol. 110, no. 2

Grosskopf, Shawna. (1993) Efficiency and productivity, in The Measurement of Productive Efficiency: Techniques and Applications, 160-194, Fried, H.O., Lovell, C.A.K. and Smith S.S. (Eds.), Oxford University Press

Hall, R.E. and C.I. Jones (1999) “Why do some countries produce more output than others?", Quarterly Journal of Economics, 114, 83-116 
Henderson, Daniel and Robert Russell (2005): "Human Capital and Convergence: A Production-Frontier Approach", International Economic Review, vol. 46, no. 4, pp. 11671205

Kumar, Subodh and R. Robert Russell (2002) “Technological Change, Technological Catchup, and Capital Deepening: Relative contributions to Growth and Convergence." The American Economic Review, June 2002, Vol. 92, No. 3, pp. 527-548

Labuske and Baten (2006) "The Technical Component of Human Capital, Schooling and Long-Run Growth in 55 Countries, 1880-1990” working paper, University of Tuebingen

Lindert, Peter H. (2004): Growing Public, vol I and II, Cambridge University Press, Cambridge, MA.

Lindert, Peter (2006) Data on Enrollment, UC Davis Homepage, downloaded 1.12.2006

Los Bart and Marcel P Timmer (2005) "The 'appropriate technology' explanation of productivity growth differentials: An empirical approach", Journal of Development Economics 77 (2), pp. 517-531

Maddison, A. (1995) Monitoring the World Economy, OECD Development Centre, Paris, Appendix K "Growth Accounts for Selected Countries" 
O’Mahoney, Mary: (1996) : “Measures of fixed capital stocks in the post-war period: a five country study", in N.F.R. Crafts and B. van Ark eds, Quantitative aspects of Post-war European Growth, Cambridge University Press.

Psacharopoulos, G. (1994) “Returns to Investment in Education: A Global Update”, World Development 22, 1325-43

Ray, S.C., (2004) Data Envelopment Analysis: Theory and Techniques for Economics and Operations Research. Cambridge University Press, Cambridge

Solow, Robert (1957) "Technical change and the Aggregate Production Function", The Review of Economics and Statistics, vol. 39, no 3, pp. 312-320

Taylor, Alan (1992) "External Dependence, Demographic Burdens and Argentine Economic Decline after the Belle Epoque", Journal of Economic History, vol. 52 no. 4, 907-36

Toniolo Gianni (1998) “Europe's Golden Age, 1950-1973: Speculations from a Long-Run Perspective”, Economic History Review vol. 51, 252-267 
Table 1. Efficiency indices

\begin{tabular}{|c|c|c|c|c|}
\hline & 1929 & & 1950 & \\
\hline & WITHOUT HC & WITH HC & WITHOUT HC & WITH HC \\
\hline ar & 1.00 & 1.00 & 0.71 & $\mathbf{0 . 8 3}$ \\
\hline at & 0.57 & 0.52 & 0.41 & 0.40 \\
\hline $\mathrm{au}$ & 0.84 & 0.75 & 0.83 & 0.84 \\
\hline be & 0.68 & 0.74 & 0.65 & 0.70 \\
\hline bg & 0.50 & 0.46 & 0.25 & 0.23 \\
\hline br & 0.58 & 0.60 & 0.44 & 0.51 \\
\hline $\mathrm{ca}$ & 0.83 & 0.78 & 0.90 & 0.90 \\
\hline $\mathrm{ch}$ & 1.00 & 0.87 & 1.00 & 1.00 \\
\hline $\mathrm{cl}$ & 0.78 & 0.90 & 0.67 & 0.79 \\
\hline $\mathrm{cn}$ & 0.31 & 0.32 & 0.16 & 0.16 \\
\hline co & 0.76 & 0.75 & 0.53 & 0.54 \\
\hline $\mathrm{cr}$ & 0.56 & 0.56 & 0.43 & 0.49 \\
\hline $\mathrm{cu}$ & 0.36 & 0.40 & 0.35 & 0.40 \\
\hline de & 0.74 & 0.68 & 0.48 & 0.49 \\
\hline $\mathrm{dk}$ & 0.86 & 0.81 & 0.76 & 0.83 \\
\hline es & 0.73 & 0.71 & 0.37 & 0.39 \\
\hline fi & 0.81 & 0.82 & 0.53 & 0.59 \\
\hline $\mathrm{fr}$ & 0.66 & 0.59 & 0.59 & 0.65 \\
\hline gr & 0.94 & 0.91 & 0.43 & 0.43 \\
\hline gt & 0.60 & 0.59 & 0.44 & 0.50 \\
\hline hu & 0.47 & 0.45 & 0.30 & 0.35 \\
\hline id & 0.69 & 0.73 & 0.37 & 0.38 \\
\hline in & 0.42 & 0.44 & 0.23 & 0.24 \\
\hline it & 0.80 & 0.78 & 0.66 & 0.67 \\
\hline jp & 0.42 & 0.41 & 0.31 & 0.29 \\
\hline $\mathrm{lk}$ & 1.00 & 1.00 & 0.50 & 0.49 \\
\hline$m x$ & 0.49 & 0.54 & 0.48 & 0.65 \\
\hline
\end{tabular}




\begin{tabular}{ccccc} 
ni & $\mathbf{0 . 6 2}$ & $\mathbf{0 . 6 3}$ & $\mathbf{0 . 3 5}$ & $\mathbf{0 . 4 2}$ \\
nl & 1.00 & 1.00 & $\mathbf{0 . 8 0}$ & $\mathbf{0 . 8 8}$ \\
no & 0.60 & 0.57 & $\mathbf{0 . 6 8}$ & $\mathbf{0 . 7 1}$ \\
nz & 0.85 & 0.99 & 0.97 \\
pl & 0.75 & $\mathbf{0 . 2 6}$ & $\mathbf{0 . 3 0}$ \\
pt & 0.31 & $\mathbf{0 . 4 5}$ & $\mathbf{0 . 5 1}$ \\
ro & 0.53 & 0.53 & $\mathbf{0 . 1 5}$ & $\mathbf{0 . 1 7}$ \\
se & 0.22 & 0.22 & $\mathbf{0 . 7 2}$ & $\mathbf{0 . 8 3}$ \\
th & 0.59 & 0.53 & 0.62 & 0.62 \\
tr & 1.00 & 1.00 & 0.32 & 0.32 \\
uk & $\mathbf{0 . 6 3}$ & $\mathbf{0 . 6 7}$ & $\mathbf{0 . 7 4}$ & $\mathbf{0 . 8 0}$ \\
us & $\mathbf{0 . 8 1}$ & $\mathbf{0 . 8 8}$ & 1.00 & 1.00 \\
uy & 1.00 & 1.00 & 1.00 & 1.00 \\
za & $\mathbf{0 . 9 3}$ & $\mathbf{0 . 9 5}$ & $\mathbf{0 . 4 1}$ & $\mathbf{0 . 5 9}$ \\
\hline mean & $\mathbf{0 . 2 8}$ & $\mathbf{0 . 3 9}$ & 0.54 & 0.58 \\
\hline
\end{tabular}


Table 2 Decomposition results 1929-1950

\begin{tabular}{|c|c|c|c|c|c|}
\hline & Prod change & EFF-1*100 & ТЕСН-1*100 & КАСC-1*100 & НАCC-1*100 \\
\hline \multirow[t]{2}{*}{ ar } & 10.34 & -16.77 & 11.70 & -1.23 & 20.16 \\
\hline & & -29.12 & 30.96 & 18.87 & $\mathrm{x}$ \\
\hline \multirow[t]{2}{*}{ at } & 0.04 & -23.94 & 13.68 & -54.19 & 152.55 \\
\hline & & -27.98 & 33.42 & 4.10 & $\mathrm{x}$ \\
\hline \multirow[t]{2}{*}{$\mathrm{au}$} & 32.48 & 11.86 & 15.20 & -0.38 & 3.20 \\
\hline & & -0.74 & 28.35 & 3.98 & $\mathrm{x}$ \\
\hline \multirow[t]{2}{*}{ be } & 25.41 & -6.17 & 20.22 & -16.22 & 32.70 \\
\hline & & -3.34 & 28.47 & 0.99 & $\mathrm{x}$ \\
\hline \multirow[t]{2}{*}{ bg } & 25.51 & -49.91 & 36.14 & -42.30 & 218.97 \\
\hline & & -51.24 & 42.47 & 80.67 & $\mathrm{x}$ \\
\hline \multirow[t]{2}{*}{ br } & 57.83 & -15.63 & 40.90 & -8.68 & 45.40 \\
\hline & & -20.90 & 49.31 & 33.63 & $\mathrm{x}$ \\
\hline \multirow[t]{2}{*}{$\mathrm{ca}$} & 53.84 & 14.82 & 21.46 & -5.78 & 17.07 \\
\hline & & 7.64 & 28.57 & 11.16 & $\mathrm{x}$ \\
\hline \multirow[t]{2}{*}{ ch } & 41.94 & 14.59 & 13.56 & 20.85 & -9.74 \\
\hline & & 0.00 & 30.92 & 8.41 & $\mathrm{x}$ \\
\hline \multirow[t]{2}{*}{$\mathrm{cl}$} & 15.60 & -12.10 & 13.63 & -10.67 & 29.56 \\
\hline & & -14.36 & 30.84 & 3.17 & $\mathrm{x}$ \\
\hline \multirow[t]{2}{*}{$\mathrm{cn}$} & -21.92 & -49.16 & 27.14 & -77.30 & 432.28 \\
\hline & & -48.09 & 29.41 & 16.24 & $\mathrm{x}$ \\
\hline \multirow[t]{2}{*}{$\mathrm{co}$} & 96.22 & -27.69 & 26.07 & 95.73 & 9.96 \\
\hline & & -24.44 & 16.33 & 123.24 & $\mathrm{x}$ \\
\hline \multirow[t]{2}{*}{$\mathrm{cr}$} & 24.12 & -13.59 & 17.61 & -36.27 & 91.64 \\
\hline & & -23.96 & 34.29 & 21.56 & $\mathrm{x}$ \\
\hline \multirow[t]{2}{*}{$\mathrm{cu}$} & 23.18 & 1.59 & 13.66 & -54.60 & 134.98 \\
\hline & & -3.95 & 30.58 & -1.79 & $\mathrm{x}$ \\
\hline \multirow[t]{2}{*}{ de } & -13.72 & -28.16 & 14.35 & -37.17 & 67.18 \\
\hline & & -16.15 & 12.66 & -8.66 & $\mathrm{x}$ \\
\hline
\end{tabular}




\begin{tabular}{|c|c|c|c|c|c|}
\hline \multirow[t]{2}{*}{$\mathrm{dk}$} & 19.00 & 2.12 & 13.68 & -3.53 & 6.26 \\
\hline & & -11.56 & 29.69 & 3.75 & $\mathrm{x}$ \\
\hline \multirow[t]{2}{*}{ es } & -23.51 & -44.76 & 16.04 & -51.51 & 146.06 \\
\hline & & -50.20 & 30.72 & 17.49 & $\mathrm{x}$ \\
\hline \multirow[t]{2}{*}{$\mathrm{fi}$} & 46.27 & -28.26 & 28.27 & -8.07 & 72.89 \\
\hline & & -35.67 & 42.68 & 59.36 & $\mathrm{x}$ \\
\hline \multirow[t]{2}{*}{$\mathrm{fr}$} & 16.28 & 9.76 & 13.57 & -32.92 & 39.05 \\
\hline & & -10.09 & 28.26 & 0.84 & $\mathrm{x}$ \\
\hline \multirow[t]{2}{*}{ gr } & -4.56 & -53.00 & 42.30 & -21.53 & 81.86 \\
\hline & & -55.13 & 50.29 & 41.55 & $\mathrm{x}$ \\
\hline \multirow[t]{2}{*}{ gt } & 21.18 & -15.69 & 20.97 & -28.58 & 66.37 \\
\hline & & -23.63 & 32.31 & 19.92 & $\mathrm{x}$ \\
\hline \multirow[t]{2}{*}{ hu } & 0.59 & -21.31 & 15.71 & -55.43 & 147.86 \\
\hline & & -35.72 & 30.93 & 19.51 & $\mathrm{x}$ \\
\hline \multirow[t]{2}{*}{ id } & -28.32 & -47.25 & 25.19 & -48.66 & 111.43 \\
\hline & & -46.66 & 24.49 & 7.95 & $\mathrm{x}$ \\
\hline \multirow[t]{2}{*}{ in } & -14.82 & -45.42 & 30.76 & -63.74 & 229.20 \\
\hline & & -44.69 & 30.43 & 18.07 & $\mathrm{x}$ \\
\hline \multirow[t]{2}{*}{ it } & 32.70 & -13.07 & 30.89 & -9.46 & 28.81 \\
\hline & & -12.83 & 40.58 & 8.28 & $\mathrm{x}$ \\
\hline \multirow[t]{2}{*}{ jp } & 3.23 & -27.58 & 21.88 & -65.93 & 243.24 \\
\hline & & -27.71 & 30.67 & 9.29 & $\mathrm{x}$ \\
\hline \multirow[t]{2}{*}{ lk } & -6.19 & -50.73 & 1.65 & -3.78 & 94.66 \\
\hline & & -50.34 & 16.52 & 62.12 & $\mathrm{x}$ \\
\hline \multirow[t]{2}{*}{$\mathrm{mx}$} & 41.92 & 19.25 & 13.64 & -24.93 & 39.49 \\
\hline & & -2.72 & 29.58 & 12.58 & $\mathrm{x}$ \\
\hline \multirow[t]{2}{*}{ ni } & -7.67 & -33.57 & 17.11 & -46.02 & 119.86 \\
\hline & & -44.28 & 35.52 & 22.27 & $\mathrm{x}$ \\
\hline \multirow[t]{2}{*}{$\mathrm{nl}$} & 6.20 & -11.62 & 14.36 & 3.46 & 1.56 \\
\hline & & -19.74 & 28.28 & 3.14 & $\mathrm{x}$ \\
\hline
\end{tabular}




\begin{tabular}{|c|c|c|c|c|c|}
\hline \multirow[t]{2}{*}{ no } & 45.31 & 24.74 & 13.56 & -20.07 & 28.34 \\
\hline & & 12.74 & 32.45 & -2.69 & $\mathrm{x}$ \\
\hline \multirow[t]{2}{*}{$\mathrm{nz}$} & 50.93 & 29.47 & 13.35 & 10.40 & -6.84 \\
\hline & & 16.84 & 28.27 & 0.71 & $\mathrm{x}$ \\
\hline \multirow[t]{2}{*}{$\mathrm{pl}$} & 22.79 & -2.55 & 13.09 & -67.06 & 238.24 \\
\hline & & -22.06 & 27.62 & 23.46 & $\mathrm{x}$ \\
\hline \multirow[t]{2}{*}{$\mathrm{pt}$} & 95.71 & -2.39 & 35.01 & 2.25 & 45.24 \\
\hline & & -16.32 & 46.31 & 59.85 & $\mathrm{x}$ \\
\hline \multirow[t]{2}{*}{ ro } & 28.55 & -24.61 & 34.32 & -75.74 & 423.19 \\
\hline & & -34.79 & 48.55 & 32.69 & $\mathrm{x}$ \\
\hline \multirow[t]{2}{*}{ se } & 82.56 & 57.18 & 12.32 & 0.70 & 2.69 \\
\hline & & 23.30 & 27.53 & 16.10 & $\mathrm{x}$ \\
\hline \multirow[t]{2}{*}{ th } & 6.39 & -37.70 & -5.97 & 4.25 & 74.22 \\
\hline & & -37.91 & 0.00 & 71.36 & $\mathrm{x}$ \\
\hline \multirow[t]{2}{*}{$\operatorname{tr}$} & 4.96 & -51.65 & 28.93 & -32.70 & 150.16 \\
\hline & & -49.62 & 30.45 & 59.70 & $\mathrm{x}$ \\
\hline \multirow[t]{2}{*}{ uk } & 16.98 & -9.46 & 21.72 & -21.14 & 34.62 \\
\hline & & -9.41 & 28.52 & 0.48 & $\mathrm{x}$ \\
\hline \multirow[t]{2}{*}{ us } & 36.67 & 0.00 & 27.84 & 5.19 & 1.64 \\
\hline & & 0.00 & 32.62 & 3.05 & $\mathrm{x}$ \\
\hline \multirow[t]{2}{*}{ uy } & 20.82 & 5.81 & 33.15 & 13.52 & -24.46 \\
\hline & & 7.43 & 47.31 & -23.65 & $\mathrm{x}$ \\
\hline \multirow[t]{2}{*}{$\mathrm{za}$} & 100.20 & 49.44 & 18.07 & -26.67 & 54.74 \\
\hline & & 45.19 & 29.48 & 6.49 & $\mathrm{x}$ \\
\hline \multirow[t]{2}{*}{ mean } & 24.03 & -12.76 & 20.41 & -21.85 & 90.15 \\
\hline & & -19.32 & 31.38 & 21.20 & $\mathbf{x}$ \\
\hline
\end{tabular}


Table 3. Regression results. Dependent variable is efficiency growth:

\begin{tabular}{|c|c|c|c|c|c|c|c|c|c|c|c|c|}
\hline \multirow[t]{2}{*}{ Model } & \multicolumn{2}{|c|}{ I I 1929-50 } & \multicolumn{2}{|c|}{ II 1929-50 } & \multicolumn{2}{|c|}{ III 1929-50 } & \multicolumn{2}{|c|}{ IV 1938-50 } & \multicolumn{2}{|c|}{ V 1938-50 } & \multicolumn{2}{|c|}{ "VI 1938-50 } \\
\hline & Coeff. & p-val. & Coeff. & p-val. & Coeff. & p-val. & Coeff. & p-val. & Coeff. & p-val. & Coeff. & p-val. \\
\hline \multicolumn{13}{|l|}{ Tariffs 1929} \\
\hline and 1938 & 0.38 & 0.63 & & & & & & & & & & \\
\hline \multicolumn{13}{|l|}{ State } \\
\hline Instititutions & & & -0.16 & 0.47 & & & & & & & & \\
\hline \multicolumn{13}{|l|}{ Lose one war } \\
\hline dummy & -0.18 & 0.10 & -0.14 & 0.25 & -0.20 & 0.03 & -0.13 & 0.09 & & & & \\
\hline \multicolumn{13}{|l|}{ Log battle } \\
\hline \multicolumn{13}{|l|}{ deaths per 1000} \\
\hline pop. & & & & & & & & & 0.00 & 0.94 & & \\
\hline \multicolumn{13}{|l|}{ Log war } \\
\hline duration & & & & & & & & & & & -0.02 & 0.03 \\
\hline \multicolumn{13}{|l|}{ Civil War } \\
\hline Dummy & -0.29 & 0.01 & -0.29 & 0.01 & -0.30 & 0.01 & -0.24 & 0.01 & -0.23 & 0.01 & -0.24 & 0.00 \\
\hline Brains to capital & 0.33 & 0.03 & 0.28 & 0.03 & 0.25 & 0.03 & 0.21 & 0.02 & 0.21 & 0.05 & 0.23 & 0.01 \\
\hline \multicolumn{13}{|l|}{ Non Europe } \\
\hline Dummy & 0.04 & 0.66 & 0.05 & 0.67 & 0.12 & 0.16 & 0.14 & 0.04 & 0.17 & 0.02 & 0.18 & 0.01 \\
\hline \multicolumn{13}{|l|}{ Price volatility } \\
\hline $1929-38$ & -0.19 & 0.36 & -0.13 & 0.20 & -0.14 & 0.11 & -0.16 & 0.03 & -0.18 & 0.02 & -0.20 & 0.01 \\
\hline Constant & 0.97 & 0.01 & 1.06 & 0.00 & 0.99 & 0.00 & 0.99 & 0.00 & 0.97 & 0.00 & 1.07 & 0.00 \\
\hline Adj.R-sq. & \multicolumn{2}{|c|}{0.43} & \multicolumn{2}{|c|}{0.34} & \multicolumn{2}{|c|}{0.37} & \multicolumn{2}{|c|}{0.39} & \multicolumn{2}{|c|}{0.33} & \multicolumn{2}{|c|}{0.43} \\
\hline $\mathrm{N}$ & \multicolumn{2}{|c|}{27} & \multicolumn{2}{|c|}{32} & \multicolumn{2}{|c|}{37} & \multicolumn{2}{|c|}{37} & \multicolumn{2}{|c|}{37} & \multicolumn{2}{|c|}{37} \\
\hline
\end{tabular}


Table 4. Descriptive Statistics, regression variables

\begin{tabular}{|c|c|c|c|c|c|}
\hline Variable & Obs & Mean & Std. Dev. & Min & Max \\
\hline \multicolumn{6}{|l|}{ Efficiency Growth } \\
\hline $1929-50$ & 41 & 0.87 & 0.27 & 0.47 & 1.57 \\
\hline \multicolumn{6}{|l|}{ Efficiency Growth } \\
\hline $1938-50$ & 41 & 0.89 & 0.22 & 0.45 & 1.32 \\
\hline Tariffs 1929 and 1938 & $29^{1}$ & 0.17 & 0.06 & 0.07 & 0.27 \\
\hline State Instititutions & $36^{2}$ & 0.56 & 0.28 & 0.12 & 1.00 \\
\hline Lose one war dummy & 41 & 0.22 & 0.42 & 0.00 & 1.00 \\
\hline \multicolumn{6}{|l|}{ Log battle deaths per } \\
\hline 1000 pop. & 41 & 0.42 & 1.89 & -5.93 & 3.93 \\
\hline \multicolumn{6}{|l|}{ Log war duration } \\
\hline (months) & 41 & 3.75 & 3.52 & 0.00 & 8.43 \\
\hline Civil War Dummy & 41 & 0.17 & 0.38 & 0.00 & 1.00 \\
\hline Brains to capital & $40^{3}$ & 0.62 & 0.35 & 0.00 & 1.28 \\
\hline Non Europe Dummy & 41 & 0.51 & 0.51 & 0.00 & 1.00 \\
\hline Price volatility $1929-38$ & $37^{4}$ & 1.45 & 0.44 & 1.06 & 3.61 \\
\hline
\end{tabular}

${ }^{1}$ Tariff data lacking for be, bg, ch, cr, fi, gt, ni, nl, pl, ro, tr, za

${ }^{2}$ Data lacking for hu, cu, bg, pl, ro

${ }^{3}$ Thailand was excluded since its capital stock was more than 100 times smaller than any other capital stock in the sample.

${ }^{4}$ Data lacking for th, $\mathrm{lk}, \mathrm{ni}, \mathrm{cr}$ 


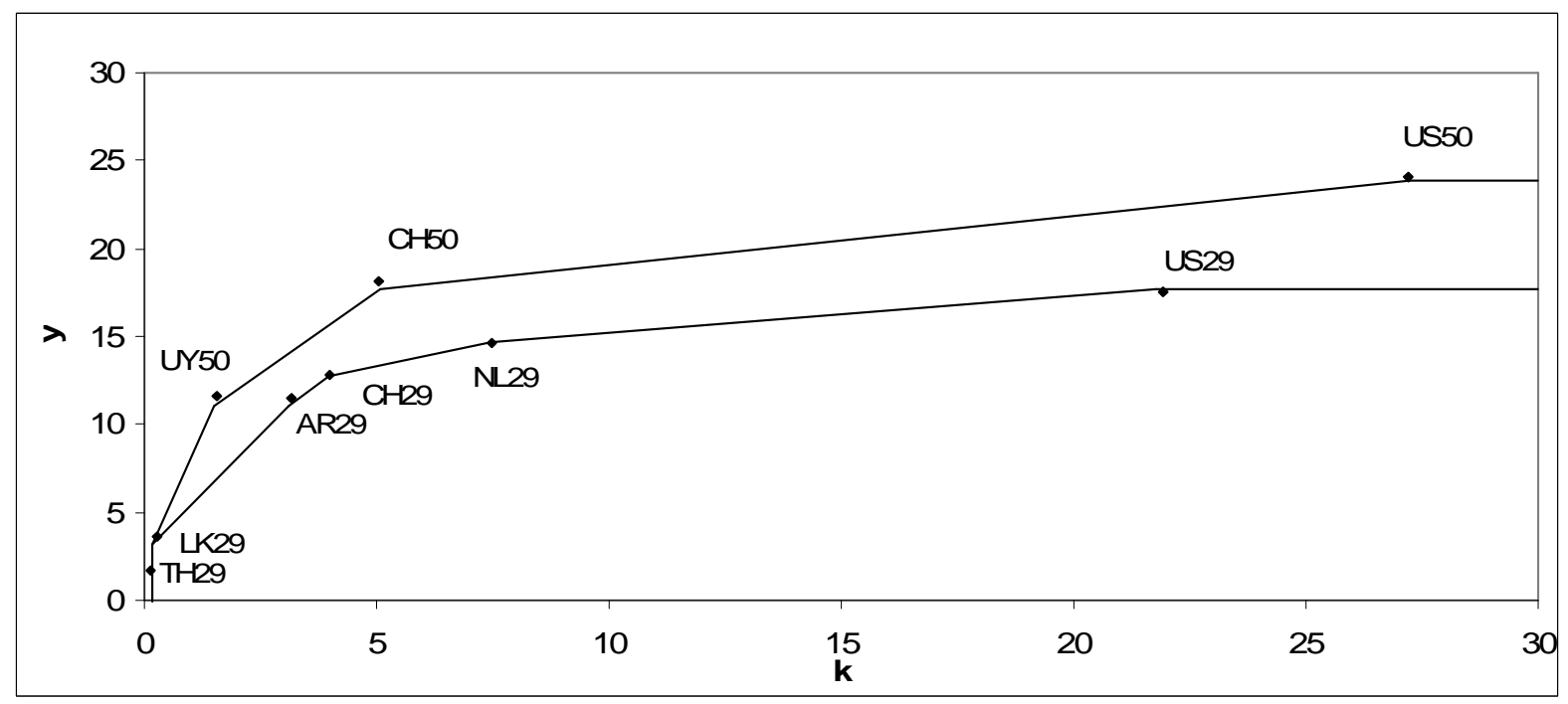

Figure 1. No Human capital inclusion. Technical frontiers in 1929 and 1950, capital and output per worker. 1000's of international 1990 US dollars

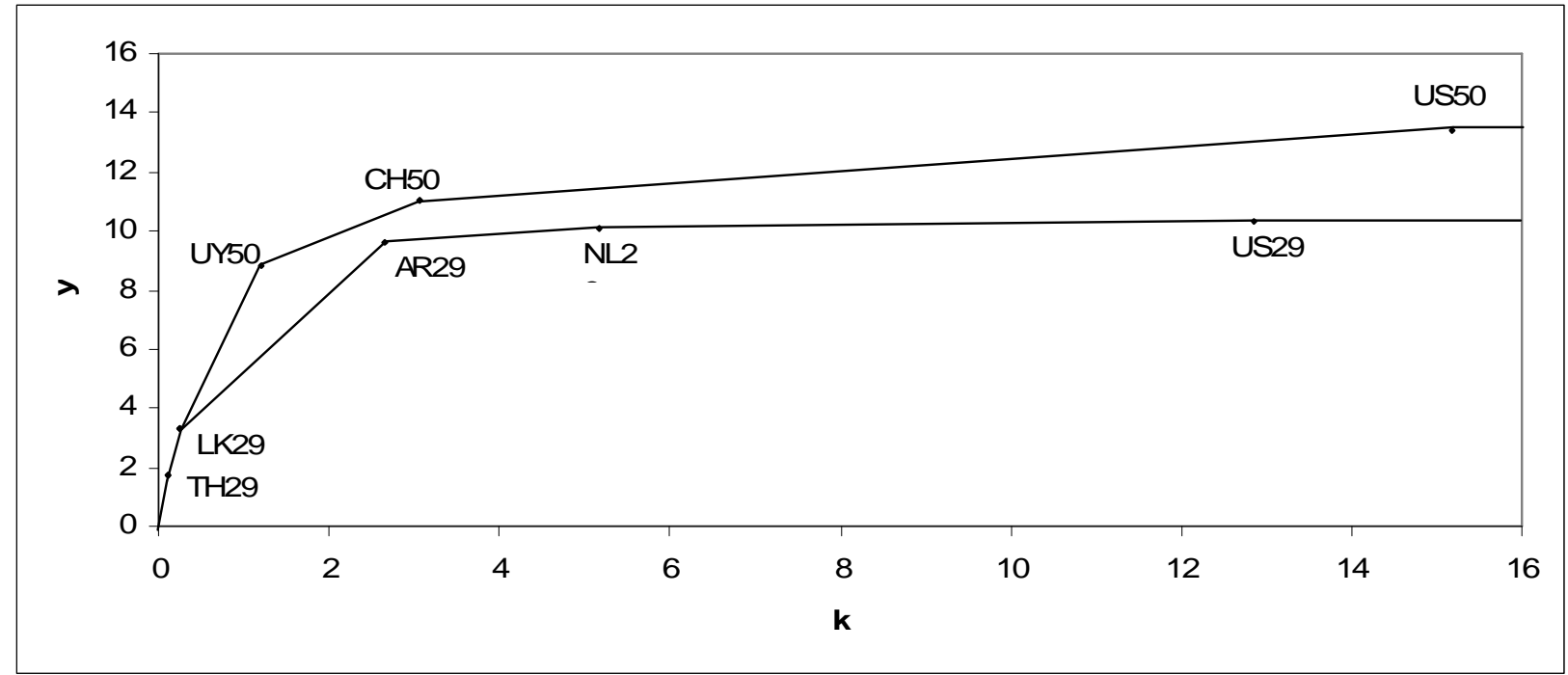

Figure 2. Human capital inclusion Technical frontiers in 1929 and 1950, capital and output at efficiency units of workers. 1000's of international 1990 US dollars 


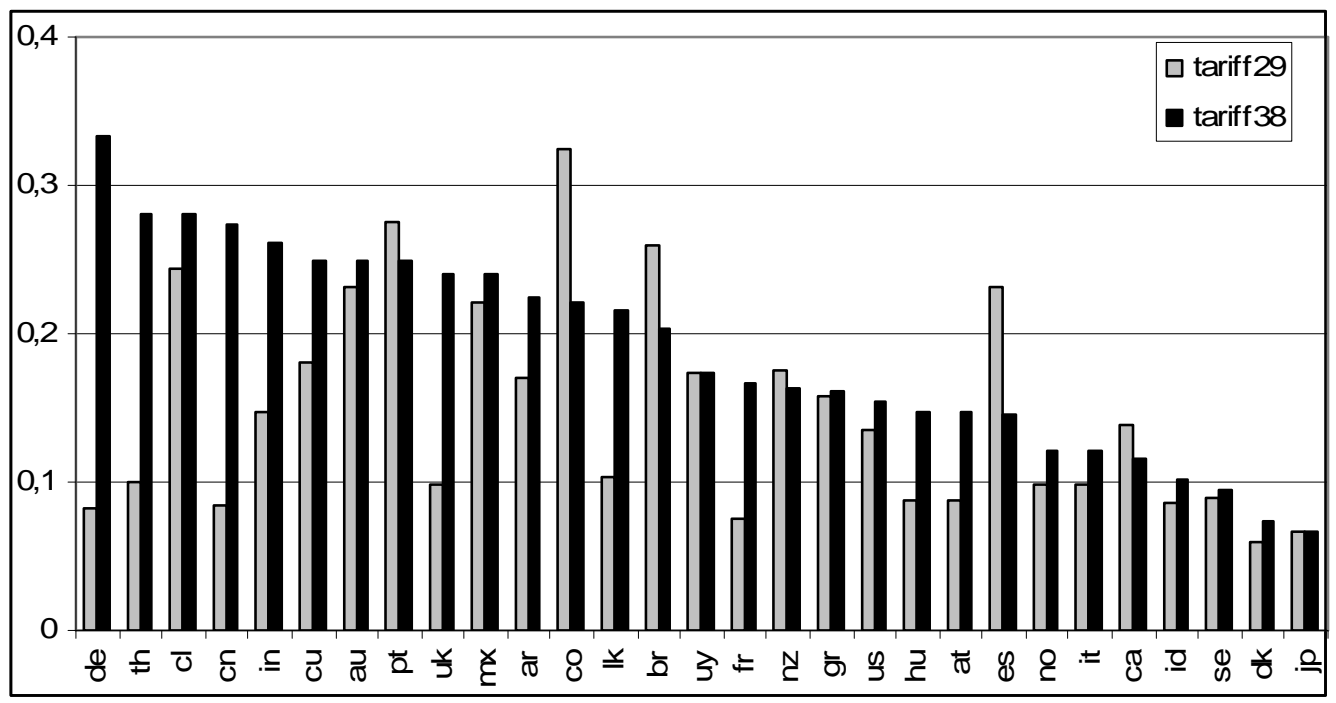

Figure 3. Average tariff rates in 1929 and 1938. Source: Clemens and Williamson (2004). 


\section{Appendix A. Physical and human capital stocks}

\section{A1: Energy based capital stocks 1929-1950:}

First we estimate the relationship between the log of energy consumption per worker and the non-residential physical capital stock from Penn World tables for 46 countries in 1965, which is the earliest year that we have data on standardised capital stocks and energy consumption for a large number of countries. The following regression was estimated:

$\log ($ capital/worker $)=13.2+0.77 * \log ($ energy/worker $)+0.74 *$ Belgium $+e$

We add a dummy for Belgium-Luxemburg in 1965, since the capital stock of BelgiumLuxemburg is very large in the PWT 5.6, probably due to the specific nature of the Luxemburgian economy. The regression has an adjusted R squared of 0.78 . Figure 4 shows that there was a very close correlation between the log of capital stock per worker and the log of energy consumption in 1965 for the 46 countries.

We use the estimated relationship between energy consumption and capital to predict historical capital per worker series for our sample of 41 countries for which we have historical energy consumption data (Darmstadter: 1971) for the benchmark years 1929, 1938 and 1950. 


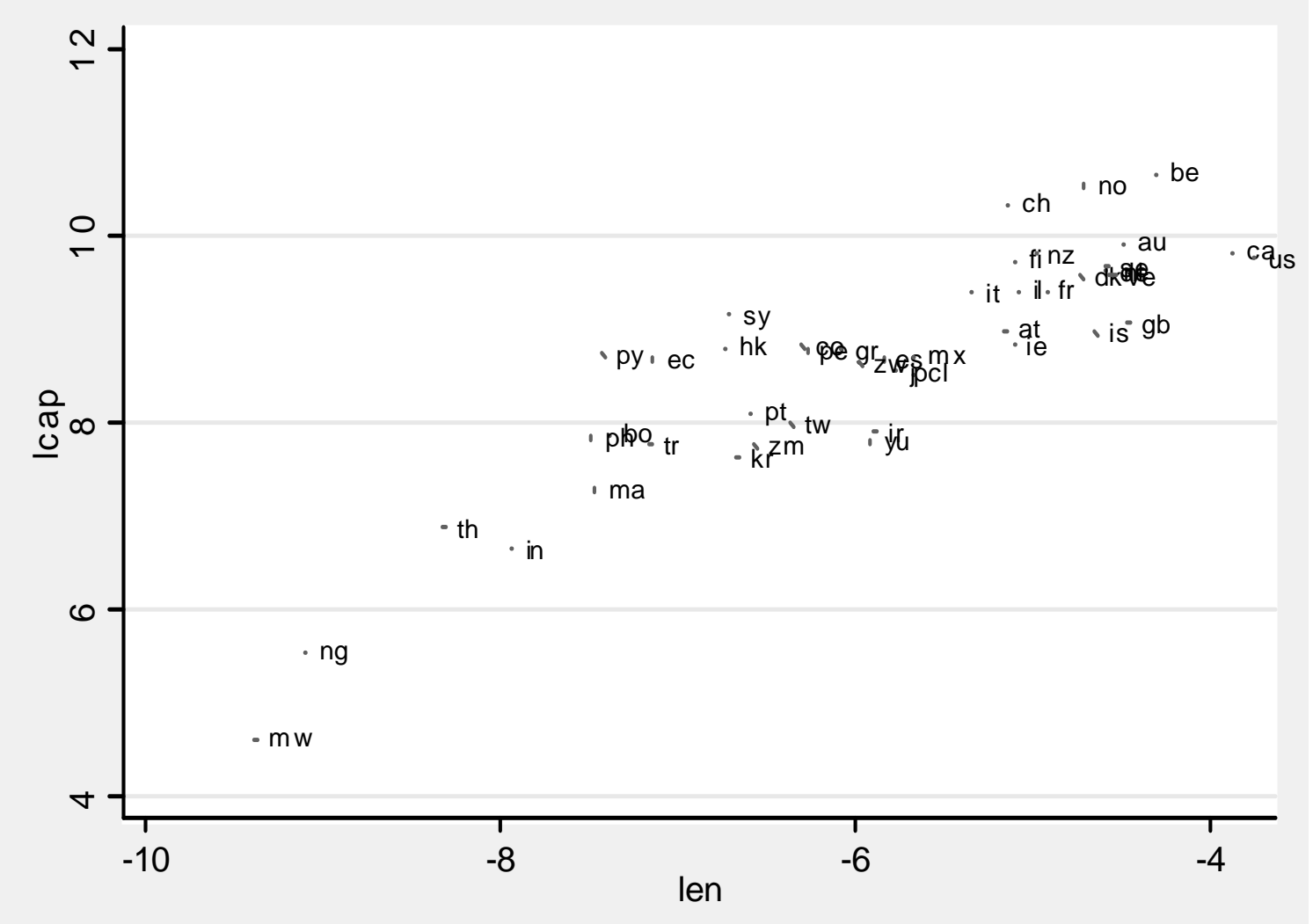

Figure 4. The log of energy consumption and capital stock per worker in 1965 for a sample of 46 countries. Energy consumption is measured in kilograms of coal equivalents per worker (Darmstadter 1971). The physical capital stock per worker is measured in 1985 US international dollars (Penn World Tables 5.6). 
Table 4 shows that our capital stocks grow at similar rates as the non-residential capital stock per worker and per efficiency unit of worker provided in Maddison (1995) for US, UK and Japan for the three benchmark years. The table also shows that capital growth per efficiency unit of worker was very modest between 1929 and 1950, both using our capital and the Maddison capital stocks.

Table 4. Growth in capital stock per worker and efficiency unit of worker 1929-1950

\begin{tabular}{lccclccc}
\hline \hline Growth in K/L & USA & UK & Japan & Growth in K/eL & USA & UK & Japan \\
\hline Maddison & 1.05 & 1.08 & 1.58 & Maddison & 0.98 & 1.02 & 1.36 \\
Enflo \& Baten & 1.24 & 1.03 & 1.18 & Enflo \& Baten & 1.15 & 0.96 & 1.01 \\
\hline
\end{tabular}

\section{A2: Human capital augmentation factors 1925-1945:}

In order to calculate the human capital augmentation factors as suggested by Hall and Jones (1999) we need the average number of school years in the population of every country. For this, we used the close correlation between the amount of primary and secondary schooling, and the average number of school years of the labour force 25 years later, using Barro's schooling data. The adjusted R-Square in a regression of school years on primary and secondary schooling is 0.84 , and this relationship is relatively time-invariant. Hence, we argue that the number of school years can be estimated based on Barro's schooling data as (the constant of -0.1267 was not statistically significant):

school years $\mathrm{t}_{\mathrm{t}}=4.2328 *$ Primary schooling s $-25+7.6492 *$ Secondary schooling $_{\mathrm{t}-25}$

We use this relationship to estimate the average number of schooling in the population of our 41 countries using Lindert (2006) and Labuske and Baten (2006) data on schooling for the benchmark years 1925, 1935 and 1945. Thereafter, we followed the strategy of Hall and Jones (1999) to calculate augmentation of labour force income by human capital, by using Mincer equation results. Those (reviewed in Psacharopoulos 1994) indicate that each of the first four 
years of schooling augment the income by $13.4 \%$, the next four years $10.1 \%$, and years of schooling beyond that $6.8 \%$.

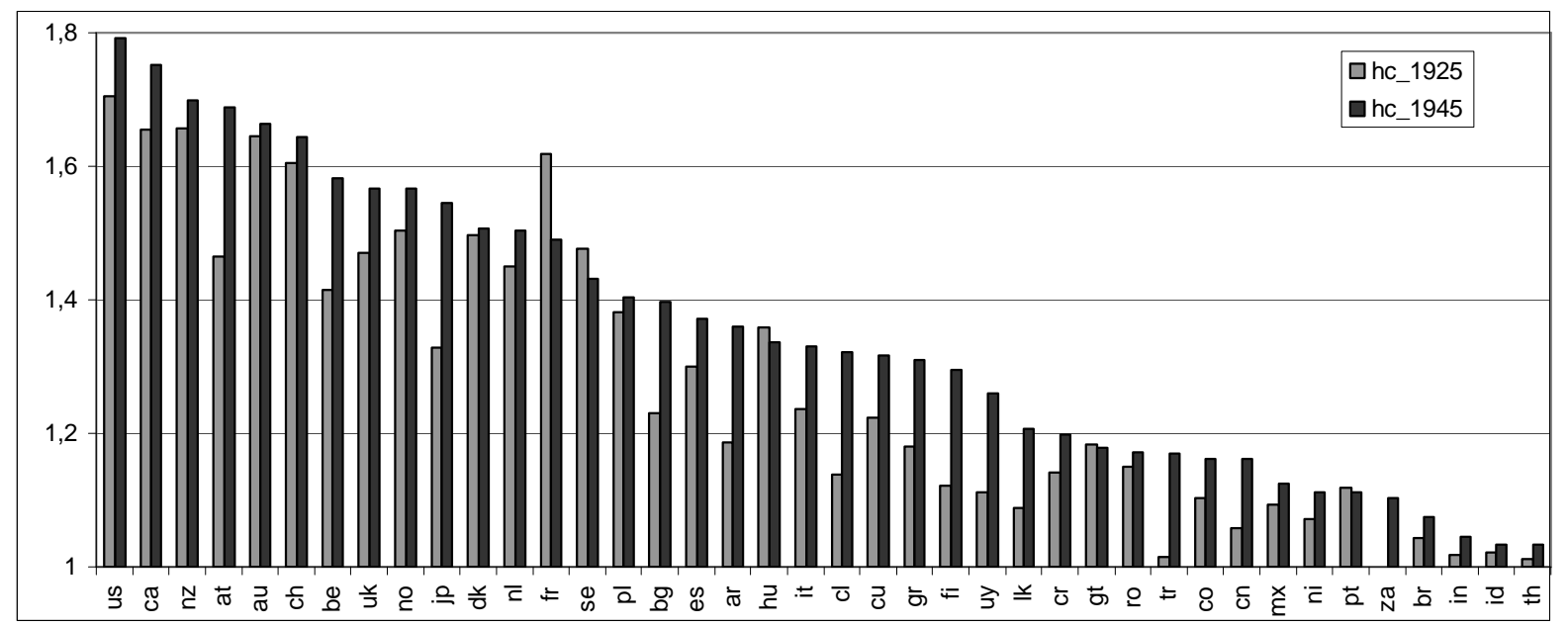

Figure 5. Human capital augmentation factors in 1925 and 1945. 